\title{
Responses of Root Endophytes to Phosphorus Availability in Peach Rootstocks With Contrasting Phosphorus-Use Efficiencies
}

\author{
Yu Zhang 1,2,3†, Xin Liu ${ }^{1,2,3 \dagger}$, Jiying Guo ${ }^{1,2,3}$, Jianbo Zhao ${ }^{1,2,3}$, Shangde Wang ${ }^{1,2,3}$, \\ Zhiqin Zheng ${ }^{1,2,3}$, Quan Jiang ${ }^{1,2,3 *}$ and Fei Ren ${ }^{1,2,3 *}$ \\ ${ }^{1}$ Beijing Academy of Forestry and Pomology Sciences, Beijing, China, ${ }^{2}$ Key Laboratory of Biology and Genetic Improvement \\ of Horticultural Crops (North China), Ministry of Agriculture and Rural Affairs, Beijing, China, ${ }^{3}$ Beijing Engineering Research \\ Center for Deciduous Fruit Trees, Beijing, China
}

\section{OPEN ACCESS}

Edited by:

Victoria Fernandez,

Polytechnic University of Madrid, Spain

Reviewed by:

Corina Carranca,

Instituto Nacional Investigaciao

Agraria e Veterinaria (INIAV), Portugal

Yong-Xin Liu,

Chinese Academy of Sciences, China

*Correspondence:

Fei Ren

30768693@qq.com

Quan Jiang

quanj@vip.sina.com

tThese authors have contributed equally to this work

Specialty section: This article was submitted to Plant Nutrition,

a section of the journa

Frontiers in Plant Science

Received: 02 June 2021

Accepted: 23 August 2021

Published: 27 September 2021

Citation:

Zhang Y, Liu X, Guo J, Zhao J,

Wang S, Zheng Z, Jiang $Q$ and

Ren F (2021) Responses of Root

Endophytes to Phosphorus Availability in Peach Rootstocks With

Contrasting Phosphorus-Use Efficiencies.

Front. Plant Sci. 12:719436. doi: $10.3389 /$ fpls.2021.719436
Phosphorus $(\mathrm{P})$ is an important macronutrient for all lives, but it is also a finite resource. Therefore, it is important to understand how to increase the $P$ availability and plant uptake. The endophytes can help host plants to improve P uptake and will be apparently affected by plant genotypes. To investigate the mechanism of root endophytes in promoting $P$ uptake of peach rootstocks, we analyzed the variations of the root endophytic fungal and bacterial communities of peach rootstocks with different $\mathrm{P}$ efficiencies under high or low level of $\mathrm{P}$ addition. Results showed that Proteobacteria was the dominant bacterial phylum in the roots of all rootstocks under the two levels of $\mathrm{P}$ addition. At low $\mathrm{P}$ level, the abundance of Actinoplanes in phosphorus-inefficiency root system was apparently higher than that at high $\mathrm{P}$ level. Actinoplanes produced important secondary metabolites, improving the stress resistance of plants. Under high $\mathrm{P}$ condition, the abundance of Ferrovibrio was higher in Qing Zhou Mi Tao than in Du Shi. Fe oxides considerably reduced the availability of applied P, which partially explained why the P utilization in Qing Zhou Mi Tao is inefficient. Further, Ascomycota was the dominant fungal phylum in the roots of all rootstocks under different levels of $\mathrm{P}$ addition. The fungi community of roots varied in different rootstocks at each $\mathrm{P}$ level, but was similar for the same rootstock at different $\mathrm{P}$ levels, which indicated that genotype had a greater effect than $\mathrm{P}$ addition on the fungal community of peach rootstocks.

Keywords: peach rootstock, phosphorus deficiency, root endophytes, bacterial community, fungal community

\section{INTRODUCTION}

Peach (Prunus persica L. Batsch) is one of the most commercially important species in the Rosaceae family and includes a wide range of cultivars. Peaches are propagated asexually by grafting. Peach rootstocks used in the production of grafted seedlings are selected based on several factors, including ease of propagation, vigor, nutrient translocation to the fruit, and resistance to pests and diseases (Souza et al., 2019). The root system of the rootstock exchanges materials with the soil environment, and the genetic and physiological characteristics of rootstocks 
vary greatly. Their root systems exhibit different ability of nutrient absorption and translocation, which leads to changes in the growth and development of the scion. Therefore, it is important to study the differences in nutrient uptake and utilization between root systems of different rootstocks to better understand the nutrition and development of peach trees and improve the quality of seedlings and fruit.

Phosphorus $(\mathrm{P})$ is one of the least mobile nutrients in soils (Liu et al., 2016a). Phosphorus is present in limited concentration in soil solution, ranging from 0.1 to 10 micromoles (Hinsinger, 2001). Moreover, due to the heterogeneous distribution of $P$ in soil, some roots still grow in a P-deficient environment even under conditions of sufficient $\mathrm{P}$ application. In response to the limited available $\mathrm{P}$ in the soil, plants evolved two mainly adaptive mechanisms: One way is to increase the efficiency of phosphorus uptake by roots and the other way is to improve the efficiency of phosphorus utilization in plants (Raghothama and Karthikeyan, 2005; Zhang et al., 2012). Another adaptation is the development of root symbioses that help plants to access otherwise unavailable Pi sources (Crombez et al., 2019). Soil microorganisms play a key role in the transformations of soil nutrients (e.g., nitrogen and P; Hu et al., 2018), and some can form mutually beneficial symbioses with plant roots. These microorganisms play an important role in the supply of soil nutrients to host plants (Jacoby et al., 2017). In grape (Vitis vinifera) and tomato (Lycopersicon esculentum), rootstock genotype can influence bacterial diversity and composition (Marasco et al., 2018; Poudel et al., 2019). The microbial community structure of apple rootstocks with different $\mathrm{P}$ efficiency was also significantly different (Chai et al., 2019).

Although several studies have catalogued the rhizosphere bacterial microbiome or fungal community, which mainly focused on crops. There has been few research on woody plants. The internal fungal and bacterial communities of woody plants remain poorly described. Therefore, the purposes of the present study were (i) to identify the most P-efficient genotype from eight peach rootstocks and (ii) to characterize the fungal and bacterial communities of peach rootstocks with different $\mathrm{P}$ efficiencies grown at different levels of $\mathrm{P}$ supply. Our findings suggest that the peach root system contains diverse niches that changed dynamically in response to soil nutrient level. It is important to explore the mechanism of efficient soil $\mathrm{P}$ utilization by peach rootstocks in order to select and breed highly P-efficient peach rootstock germplasm.

\section{MATERIALS AND METHODS}

\section{Plant Materials and Growth Conditions}

The experiment was conducted in a greenhouse of Beijing Academy of Forestry and Pomology Sciences, Haidian District, Beijing, China, using eight peach rootstocks: Du Shi, Da Lian Ri Ben, Bei Da Yu, Qing Zhou Mi Tao, Tsukuba 3, Tsukuba 6, San Kuai Shi, and GF677. All plant materials were offered by the National Germplasm Repository for Peach and Strawberry in Beijing. Maturing peaches with uniform size were collected, and the shell was removed to obtain the seeds. The seeds were surface sterilized with $75 \%$ alcohol, rinsed three times with distilled water, placed in a petri dish with cotton, and stored at $4^{\circ} \mathrm{C}$. After 90 days, the germinated seeds were transferred to individual pots. Initially, the plants were irrigated with deionized water every 2 days. After 1 week, they were irrigated with $200 \mathrm{ml}$ of nutrient solution every 2 days. The nutrient solution contained either $1 \mathrm{~mol} / \mathrm{L} \mathrm{P}$ (high $\mathrm{P}, \mathrm{HP}$ ) or $0 \mathrm{~mol} / \mathrm{L} \mathrm{P}$ (low P, LP). The concentrations of the other nutrients were those of standard Hoagland's nutrient solution. Each treatment was replicated four times. Each treatment includes 20 plants.

\section{Plant Harvest and Measurements}

After 30 days, four plants from each of the eight peach rootstocks were selected and divided into shoots and roots. Four plants were selected from each treatment for measurement of plant height. After measuring the fresh weight, all plant samples were placed in a $105^{\circ} \mathrm{C}$ oven for $30 \mathrm{~min}$ to deactivation of enzymes and then dried to a constant weight at $75^{\circ} \mathrm{C}$. The dried materials were ground to a fine powder through $1 \mathrm{~mm}$ sieve. Total P concentration of shoots and roots was measured using a modified Kjeldahl digestion and the vanado-molybdate automated colorimetric method described in Peng et al. (2012). For fungal and bacterial community analyses, root samples from six plants were obtained from Du Shi (D) and Qing Zhou Mi Tao (Q) grown at both P levels. Plants were removed from the pots and rinsed with pure water. Fresh root samples were wiped with paper, wrapped it in tin foil, and put immediately into liquid nitrogen. These samples were stored at $-80^{\circ} \mathrm{C}$ for downstream microbiome analysis. According to the growth status and phosphorus utilization efficiency of the eight rootstocks, $\mathrm{Du}$ Shi was a phosphorus efficient peach rootstock and the other seven peach rootstocks were phosphorus-inefficient rootstocks. Therefore, in this article, only one phosphorusinefficient rootstock (Qing Zhou Mi Tao) was selected for comparison with Du Shi to determine the root system microbial community structure.

\section{Analysis of Root Endophyte Community Extraction of Genomic DNA and Amplicon Generation}

Total genomic DNA was extracted from samples using the CTAB method. 1\% agarose gel was used to determine DNA concentration and purity. Then, the DNA concentration was diluted to $1 \mathrm{ng} / \mu \mathrm{l}$ with sterile water (Du et al., 2020). 16S rRNA/ITS genes of distinct regions (16S V4-V5, ITS1) were amplified using specific primers with barcodes (Schoch et al., 2012; Chai et al., 2019).

\section{Quantification and Purification of PCR Products, Library Preparation, and Sequencing}

An equal volume of $1 \times$ loading buffer (containing SYBR green) was mixed with the PCR products, and they were separated by electrophoresis on a $2 \%$ agarose gel. The PCR products were mixed in equidensity ratios, and the mixed products were purified with a Qiagen Gel Extraction Kit (Qiagen, Germany). 
The library was sequenced on the Illumina NovaSeq platform to generate 250 -bp paired-end reads.

\section{Statistical and Bioinformatic Analyses}

Two-way ANOVA was conducted to test the effects of genotype, $\mathrm{P}$ levels, and their interactions on plant physiological traits (plant height, shoot fresh weight, root weight, and $\mathrm{P}$ utilization efficiency). The effects of genotype on plant physiological traits were analyzed by using one-way ANOVA, followed by post-hoc tests (Tukey' HSD) in each $\mathrm{P}$ addition treatment, and the effect of $\mathrm{P}$ addition by t-test in each peach genotype rootstock, respectively.

For microbial community analysis, the raw forward and reverse reads from each sample were joined at their overlapping ends using a minimum overlap of 50 nucleotides and a maximum of one mismatch within the overlapping region with the fastqjoin algorithm. ${ }^{1}$ The reads were then quality screened using a minimum PHRED score of Q20. Use UPARSE ${ }^{2}$ to organize the sequence (Caporaso et al., 2010), and the QIIME software (ver. 1.8.0, http://qiime.org) was used to analyze the resulting data. The sequences were clustered into operational taxonomic units (OTUs) at a similarity level of $97 \%$ to calculate the Chaol richness estimator and the Shannon diversity index. The Ribosomal Database Project Classifier tool was used to classify all sequences into different taxonomic groups ${ }^{3}$ (Quast et al., 2013).

Student's t-tests were performed to compare the bacterial diversity of roots from given rootstocks and $\mathrm{P}$ conditions, and MetaStat software (MetaStat, Inc., Boston, MA) was used to compare the fungal diversity. The relative abundances of bacterial and fungal taxa were determined, and statistical analyses were based on the false discovery rate-corrected Kruskal-Wallis test $(p<0.05)$. The variations in bacterial and fungal community composition of root were analyzed using the permutational multivariate (PERMANOVA, 999 permutations) and visualized by principal coordinates analysis plots (PCoA, based on the Bray-Curtis distance matrices). All statistical analyses and visualizations were performed in R.4.0.5 ( $\mathrm{R}$ Development Core Team). ${ }^{4}$

\section{RESULTS}

\section{Plant Morphological and P Uptake}

Genotype and $\mathrm{P}$ level had an highly significant effect on the height of eight peach rootstocks, and there was a significant effect between genotype and $\mathrm{P}$ level on the height $(p<0.05$; Figure 1A). Under the HP level, the height of Tsukuba 3 and Tsukuba 6 was higher than the other six peach rootstocks, and the heights of Du Shi, GF677, and San Kuai Shi were significantly lower than other peach rootstocks. Under LP level, the height of Tsukuba 3 and

${ }^{1}$ https://expressionanalysis.github.io/ea-utils/ ${ }^{2}$ https://pubmed.ncbi.nlm.nih.gov/23955772/

${ }^{3}$ http://www.arb-silva.de/

${ }^{4}$ https://www.R-project.org/
Tsukuba 6 was similar to that of HP supply, both of which were significantly higher than the other peach rootstocks. GF677 had the lowest height under low phosphorus conditions. The height of Du Shi was not significantly different at both $\mathrm{P}$ levels, and the same was true for Tsukuba 6 (Figure 1A). Significant interaction of genotype and P level was observed for shoot fresh weight (FW; $p<0.001$; Figure 1B). Under HP level, shoot fresh weight of Bei Da Yu, GF677, Qing Zhou Mi Tao, and Tsukuba 6 was significantly greater than that of Du Shi, San Kuai Shi, and Tsukuba 3, but not significantly different from those of $\mathrm{Da}$ Lian $\mathrm{Ri}$ Ben (Figure 1B). The shoot fresh weight of Tsukuba 6 remained the heaviest under low $\mathrm{P}$ treatment. There were no significant differences in shoot fresh weight between both phosphorus supply for Du Shi and for Tsukuba 3 (Figure 1B). Varieties significantly differed in the root fresh weight (Figure 1C). Across all $\mathrm{P}$ treatments, the root fresh weight of Bei Da $\mathrm{Yu}$ was significantly greater than that of the other seven peach rootstocks (Figure 1C). The interaction of genotype and $\mathrm{P}$ level had a significant effect on root fresh weight $(p<0.05)$. The fresh weight of roots of $\mathrm{Du}$ Shi was not significantly different under the two phosphorus levels, and the root growth of the other seven peach rootstocks was significantly inhibited by low phosphorus availability.

The level of phosphorus supply had an highly significant effect on $\mathrm{P}$ utilization efficiency (PUE) of eight peach rootstock (Figure 2). Phosphorus utilization efficiency was higher in all eight rootstocks under LP conditions than under HP conditions (Figure 2). Genotype effect on PUE was also highly significant, and there were differences in PUE among peach rootstocks of different genotypes at the same level of $\mathrm{P}$ supply. The $\mathrm{P}$ utilization efficiency of $\mathrm{Du}$ Shi was significantly greater than that of the other seven rootstocks under LP. Although PUE of Du Shi was the lowest under high phosphorus conditions, it was the highest when phosphorus deficiency stress was encountered. Across plant growth conditions, the growth of the other seven peach rootstocks was inhibited to different degrees under low $\mathrm{P}$ conditions, but the growth condition of $\mathrm{Du}$ Shi was not suppressed. In summary, we concluded that Du Shi was a P-efficient rootstock.

\section{Root Endophytic Bacterial Community Composition Differs Between Rootstocks Under Different P Conditions}

Using high-throughput sequencing, we analyzed the root endogenic bacterial diversity and composition of the two rootstocks at two $\mathrm{P}$ levels. In total across the two rootstocks, we defined that there were 876 OTUs and 843 OTUs under HP and LP conditions, respectively. Under LP conditions, 224 OTUs were detected only in Du Shi, and 145 were detected only in Qing Zhou Mi Tao, indicating that the two rootstocks had distinct bacterial community structures. Under the conditions of high phosphorus, Du Shi had 159 special OTUs, and 230 OTUs were specific to Qing Zhou Mi Tao (Figure 3A). Good's coverage values were greater 


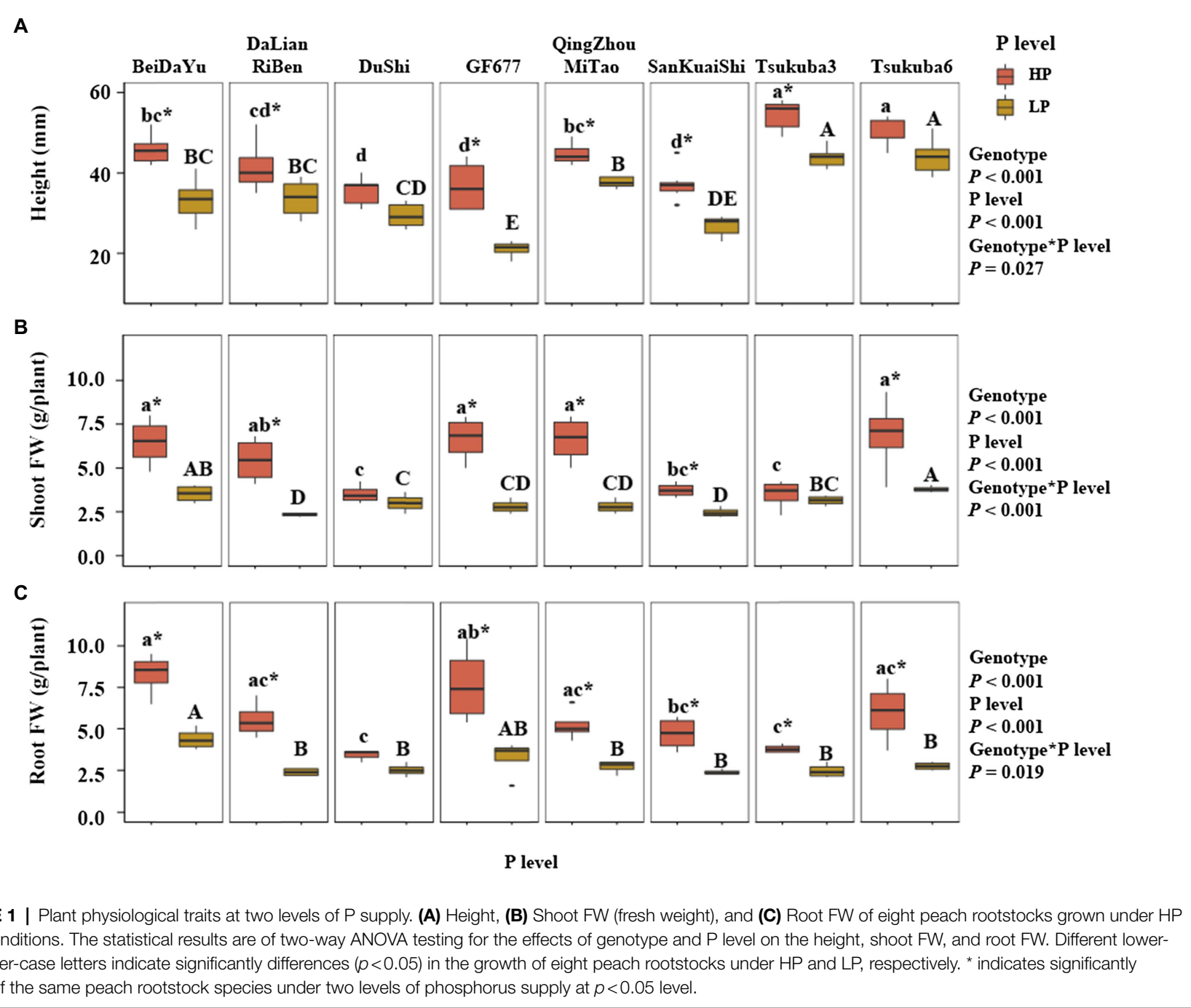

than $99 \%$, indicating that the sequencing depth was sufficient. The Chaol diversity estimator of the bacterial microbiome ranged from 566.52 to 691.86 , and the Shannon diversity estimator ranged from 4.30 to 5.19 (Table 1). To investigate how rootstocks and $\mathrm{P}$ levels affect the community structure of root-inhabiting bacteria, we classified OTUs at the phylum level (Figure 3B). Some taxa, such as Proteobacteria, were abundant in all rootstocks and $\mathrm{P}$ levels (Figure 3B). Proteobacteria was the dominant bacterial phylum in $\mathrm{DH}$ (76.9\%), DL (76.9\%), QH (75.7\%), and QL (77.8\%). The relative abundance of Actinoplanes was significantly lower in $\mathrm{QH}$ than in QL (Figure 3C). Actinoplanes belongs to the phylum Actinobacteriota. Meanwhile, Ferrovibrio belongs to the Proteobacteria phylum, and its abundance in $\mathrm{QH}$ was higher than that in DH treatment (Figure 3C).

Principal coordinates analysis plots showed that the structure of bacterial and fungal communities differed among $\mathrm{DH}$ (Du Shi of high phosphorus), DL (Du Shi of low phosphorus), QH (Qing Zhou Mi Tao of high phosphorus), and QL (Qing Zhou Mi Tao of low phosphorus). The first and second axis accounted for 45 and $21 \%$, respectively, of the total variation in the bacterial communities in the root of Du Shi and Qing Zhou Mi Tao, and the Du Shi was clearly separated from the Qing Zhou Mi Tao $(p<0.05)$, which indicated that the community structure of the root bacteria was significantly different between the two rootstocks (Figure 4A). Phosphorus levels had a significant effect on the root bacterial community of peach rootstock $(p<0.05)$. The interaction between phosphorus level and genotype had no significant effect on the bacterial community structure in the root systems of the two peach rootstocks $(p=0.242)$.

\section{Root Endophytic Fungal Community Composition Differs Between Rootstocks Under Different P Conditions}

There were 45 and 21 unique fungal OTUs in $\mathrm{DH}$ and $\mathrm{QH}$ roots, respectively, and 35 and 19 unique fungal OTUs in DL and $\mathrm{QL}$ roots. $\mathrm{DH}$ and $\mathrm{QH}$ shared a large number of fungal OTUs (45.5\% of total fungal OTUs), and DL and QL shared 


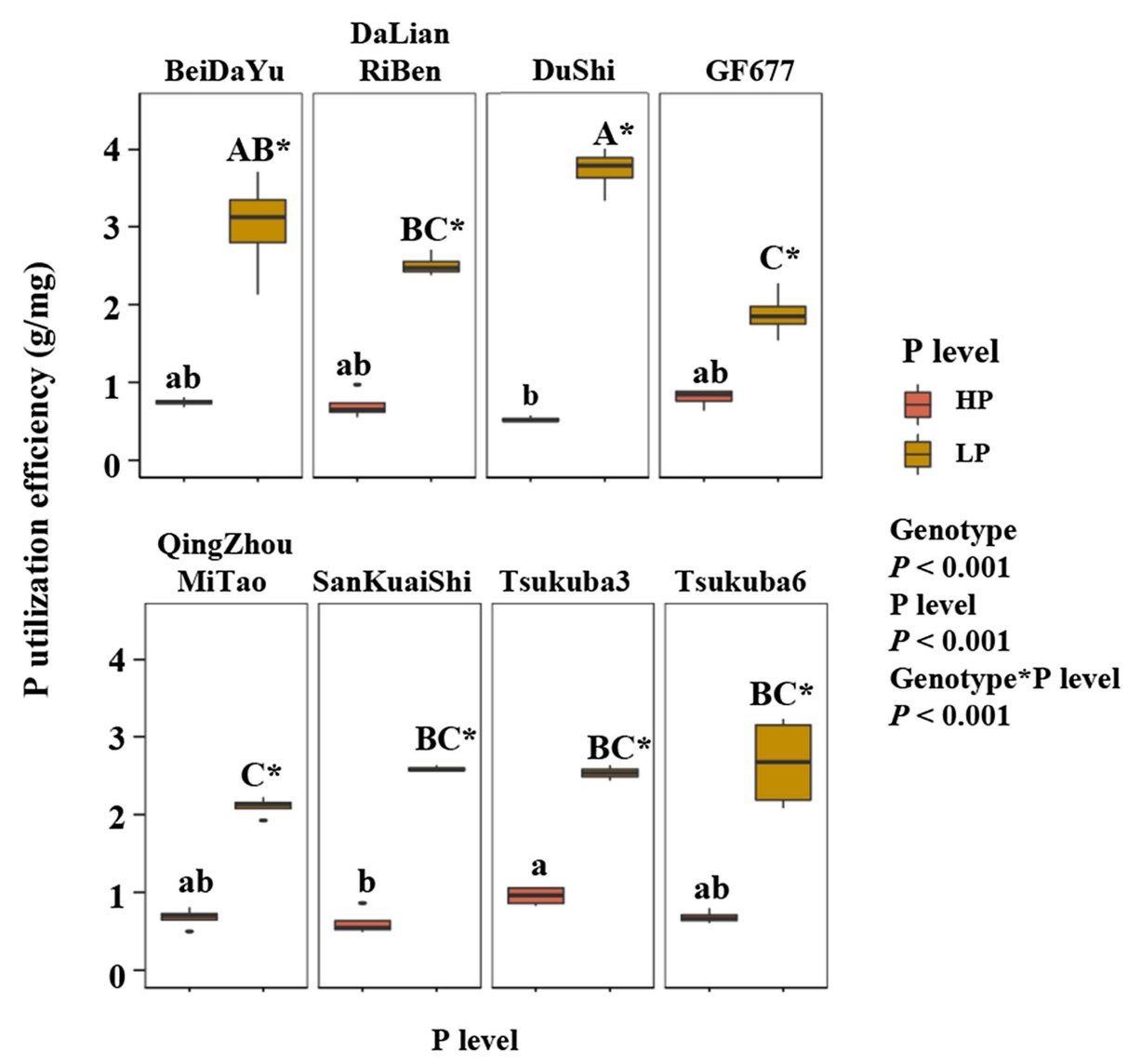

FIGURE 2 | Phosphorus (P) utilization efficiency (PUE) of eight peach rootstocks under HP and LP. The statistical results are of two-way ANOVA testing for the effects of genotype and P level on PUE. Different lower- and upper-case letters indicate significantly differences $(p<0.05)$ in PUE of eight peach rootstocks under HP and LP, respectively. ${ }^{*}$ indicates significantly effects of the same peach rootstock species under two levels of phosphorus supply at $p<0.05$ level.

$48.6 \%$ of total fungal OTUs (Figure 5A). Based on the taxonomic affiliations of the OTUs, five fungal phyla were found in the root of peach rootstocks with different $\mathrm{P}$ efficiency (Figure 5B). Ascomycota was the dominant fungal phylum in all samples (Figure 5B). GS16, belonged to phylum of Aphelidiomycota, was more abundant in $\mathrm{DH}$ roots than in $\mathrm{QH}$ roots (Figure $5 \mathrm{C}$ ). There were no other significant differences in fungal abundance at the phylum level. However, the relative abundance of Gibberella_intricans was significantly greater in DL than in $\mathrm{QL}$ at the species level (Figure 5C). Good's coverage index was greater than $99.9 \%$ across all rootstocks and $\mathrm{P}$ treatments. $\mathrm{Du}$ Shi had a higher value of Chaol than Qing Zhou Mi Tao under low $\mathrm{P}$ conditions, and the Shannon diversity estimator ranged from 0.70 to 0.88 in the fungal microbiome (Table 2).

In addition, PCoA showed that fungal composition of microbial communities differed among all treatments (Figure 4B). It displayed that the first and second axis accounted for 75 and $8 \%$, respectively (Figure 4B). The PERMANOVA results showed a similar result as the bacterial community structure. Genotype had a significant effect on the root fungal community structure of both peach rootstocks $(p<0.05)$, while phosphorus levels $(p=0.880)$ and the interaction between the two $(p=0.950)$ had no effect.

\section{DISCUSSION}

\section{Responses of Different Rootstocks to P Deficiency}

Phosphorus is one of the most commonly deficient plant nutrients in soils (Raghothama and Karthikeyan, 2005). Modern agricultural practices are largely reliant on fertilizer applications to ensure high yields, particularly in China orchards (Li et al., 2010). But the situation of phosphate fertilizer is not optimistic. Phosphorus fertilizer is made from the rock phosphate (Cordell et al., 2009). Rock phosphate reserves are expected to be exhausted in the next 50-100 years (Johnston et al., 2014). The study suggested that the selected P-efficient genotypes could be used to enhance PUE (Cong et al., 2021). Thus, screening for highly P-efficient genotypes is of great importance (Zhao et al., 2018). One of the characteristics of P-efficient genotypes is high PUE, i.e., the amount of $\mathrm{P}$ obtained from the soil that is translocated, remobilized, and utilized for plant physiological processes (Powers et al., 2020). Phosphorus utilization efficiency and relative PUE under low phosphorus condition were used to screen high P efficiency soybean varieties (Wang et al., 2021). In our research, when $\mathrm{Du}$ Shi was in sufficient phosphorus 
A

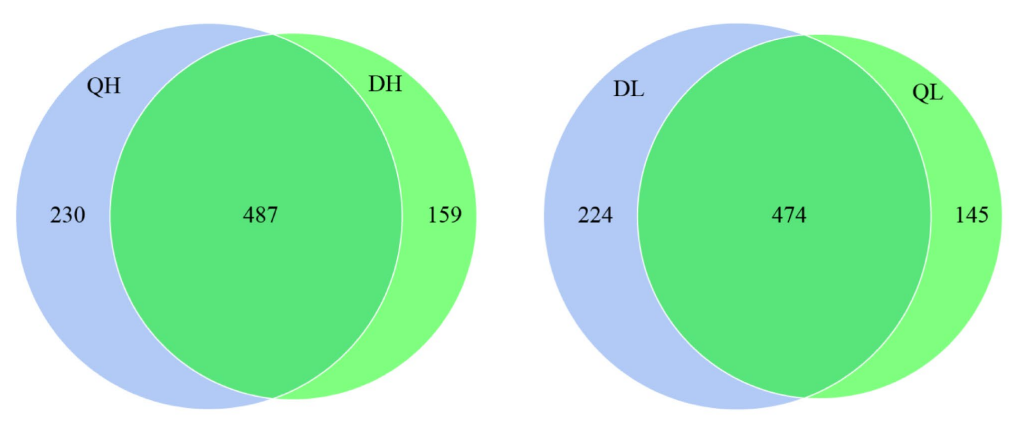

B

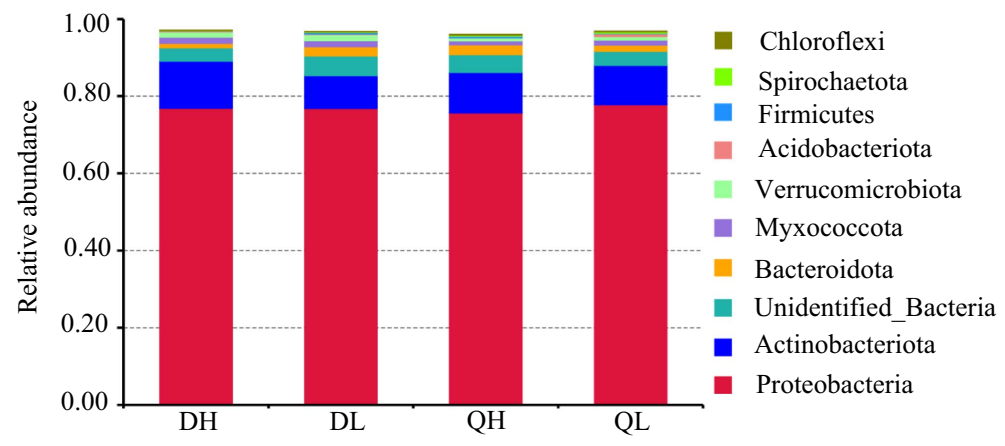

C
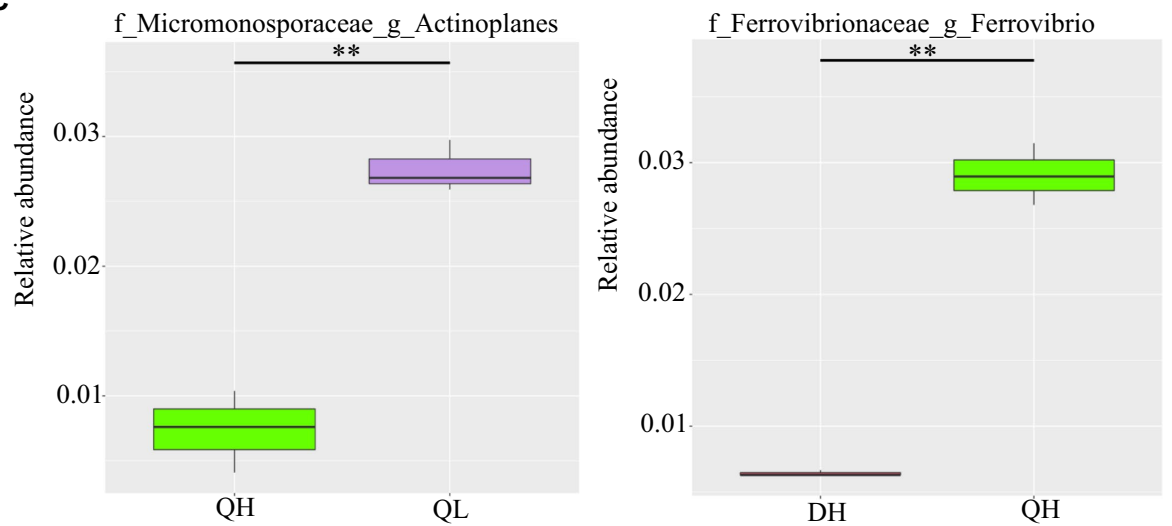

FIGURE 3 | Relative abundance of bacterial taxonomic units in roots of Du Shi and Qing Zhou Mi Tao grown at LP or HP supply. (A) Numbers of differentially enriched bacterial operational taxonomic units (OTUs) in Du Shi and Qing Zhou Mi Tao roots. (B) Relative abundance of bacteria taxa at the phylum level in Du Shi and Qing Zhou Mi Tao roots. (C) Specific genus enriched in Du Shi and Qing Zhou Mi Tao roots under HP or LP conditions. **p<0.01, Student's t-test. DH, Du Shi under HP; DL, Du Shi under LP; QH, Qing Zhou Mi Tao under HP; and QL, Qing Zhou Mi Tao under LP.

TABLE 1 | Root bacterial abundance and diversity of peach rootstocks under high $\mathrm{P}(\mathrm{HP})$ and low $\mathrm{P}(\mathrm{LP})$ conditions.

\begin{tabular}{|c|c|c|c|}
\hline Sample group & Coverage (\%) & Chao 1 & Shannon \\
\hline $\mathrm{DH}$ & $99.50 \pm 0.00 a$ & $691.86 \pm 145.48 a$ & $4.76 \pm 0.013 a$ \\
\hline $\mathrm{DL}$ & $99.60 \pm 0.00 a$ & $566.52 \pm 26.91 a$ & $5.19 \pm 0.44 a$ \\
\hline $\mathrm{QH}$ & $99.53 \pm 0.00 a$ & $614.61 \pm 69.40 a$ & $4.92 \pm 0.240 a$ \\
\hline QL & $99.46 \pm 0.00 a$ & $660.64 \pm 66.62 a$ & $4.30 \pm 0.19 a$ \\
\hline
\end{tabular}

Within a column, means followed by the same letter are not significantly different $(p<0.05)$.

supply, PUE was not too obvious. However, PUE of Du Shi increased rapidly when plants grew under low phosphorus stress, making the growth proceed normally (Figures 1, 2).
Therefore, Du Shi is a phosphorus efficient peach rootstock that can be directly used for production under low extractable $\mathrm{P}$ concentration in soil.

\section{Root Microbial Community Structure and Taxonomy in Two Peach Rootstocks Under Different $\mathbf{P}$ Levels}

Previously, much research on root microorganisms of woody plants has focused on the rhizosphere, but few studies have considered the microbes that live inside the root system. For example, the different $\mathrm{P}$ efficiency of apple rootstock root system can recruit different kinds of microorganism (Chai et al., 2019). But what about the microbial structure 
A

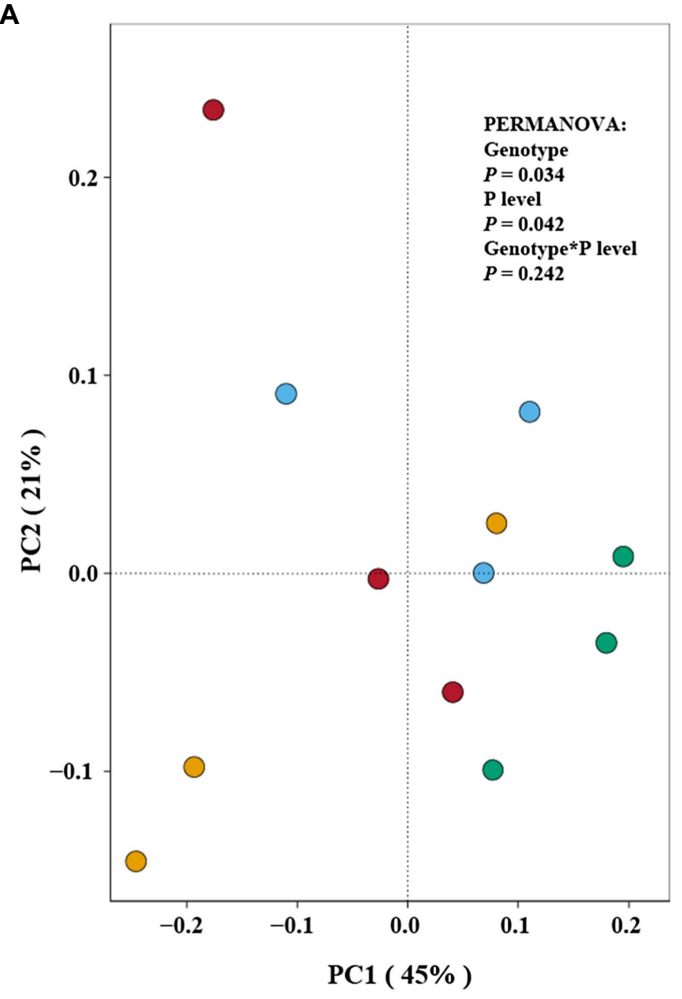

B

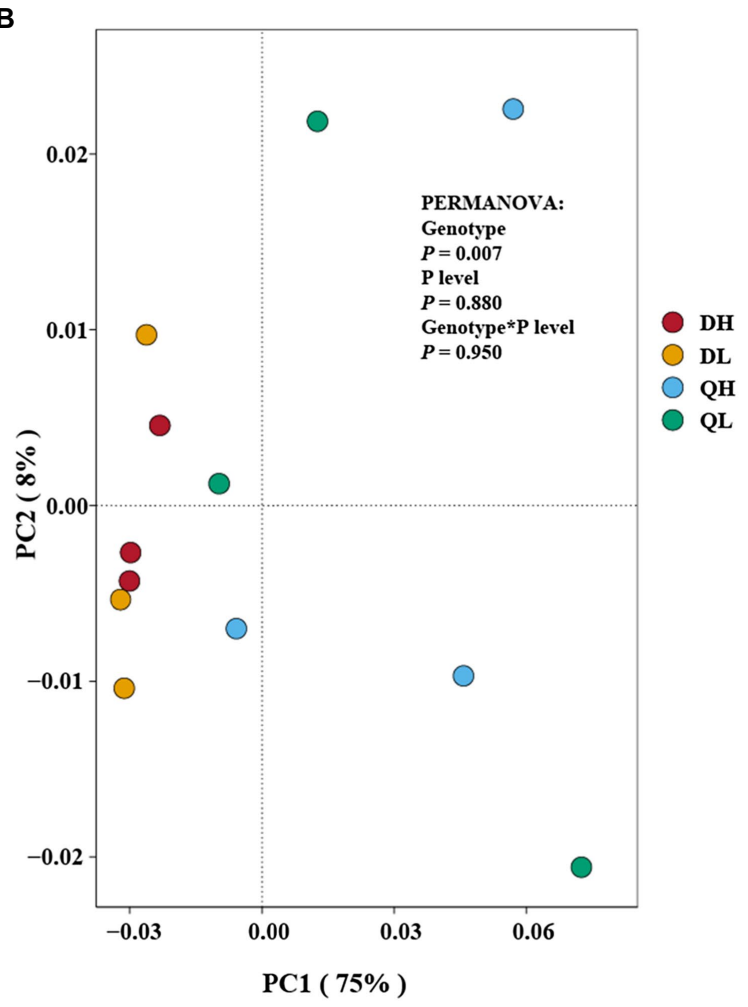

FIGURE 4 | Principal coordinates analysis of Du Shi (D) and Qing Zhou Mi Tao (Q) under HP or LP on the root bacterial (A) and fungal (B) community composition. The statistical results are of permutational multivariate ANOVA testing for the effects of genotype and P level on bacterial and fungal community composition.

within in the root systems of different rootstocks? In this study, we taxonomically characterized root endophytic microbes in P-efficient and P-inefficient peach rootstocks at two $\mathrm{P}$ levels. Bacteria play determining roles in soil and contribute to essential functions in the cycling of nutrient (e.g., nitrogen and phosphorus; Pankratov et al., 2011; Su et al., 2015; Zhang et al., 2019). The results of this study showed that the bacterial community within the root system of peach rootstock was influenced merely by genotype and P levels, and not by the interaction between the two variables (Figure 4A). The bacterial diversity (Shannon index) did not differ significantly between the two rootstocks at each $\mathrm{P}$ level (Table 1), but the bacterial community structure differed significantly at the genus level between the rootstocks and $\mathrm{P}$ treatments (Figure 3C). The phylum Proteobacteria dominated the root bacterial communities (Figure 3B), consistent with the results of several previous bacterial community studies on crop rhizosphere soils (Mendes et al., 2014; Samaddar et al., 2019), mining soils (Li et al., 2015; Wei et al., 2019), and P-enriched soils (Hu et al., 2020). The Proteobacteria is widespread in the soil environment (Niu et al., 2020). The special Proteobacteria is responsible for converting solar energy into chemical energy through photosynthesis (Berthrong et al., 2014).

At low P level, the abundance of Actinoplanes in Qing Zhou Mi Tao root system was significantly higher than those at high P level. Actinoplanes has two main functions: First, Actinoplanes strains possess a highly sophisticated life cycle that includes differentiating sporangia and motile spores, and second, Actinoplanetes produce a plethora of structurally complex and pharmaceutically important secondary metabolites (Yushchuk et al., 2020). Some secondary metabolites can improve the stress resistance of plants. Under higher $\mathrm{P}$ conditions, the abundance of Ferrovibrio was higher in Qing Zhou Mi Tao than in Du Shi (Figure 3C). Ferrovibrio can oxidize $\mathrm{Fe}(0)$ to $\mathrm{Fe}(\mathrm{III})$ (Zhang et al., 2018; Shi et al., 2019; Liu et al., 2020). Fe oxides in the growing media strongly and negatively affected plant development and $\mathrm{P}$ uptake (García-López et al., 2021). Fe oxides considerably reduced the efficiency of applied P (García-López and Delgado, 2016). This is one of the reasons why the phosphorus in Qingzhou Mi Tao is inefficient.

Previous work has documented that there were significantly differences in the fungal communities between root systems (Yu et al., 2017), confirming that roots provide a selective environment for microbes (Bulgarelli et al., 2012; De Souza et al., 2016). Strikingly, Ascomycota accounted for more than 95\% of the fungal OTUs across all treatments (Figure 5B). Furthermore, the relative abundance of GS16 (Aphelidiomycota phyla) and Gibberella differed significantly between the roots of Du Shi and Qing Zhou Mi Tao. Aphelidiomycota is not a typical soil and root fungus; little is known about it, and 
A

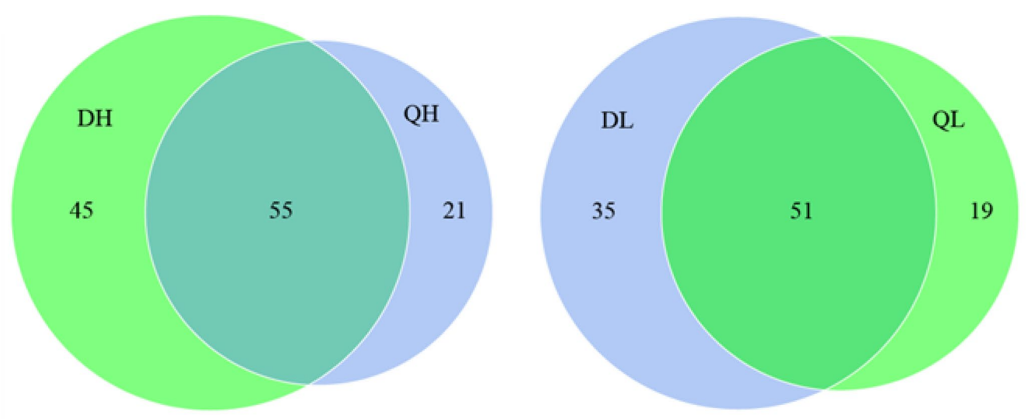

B

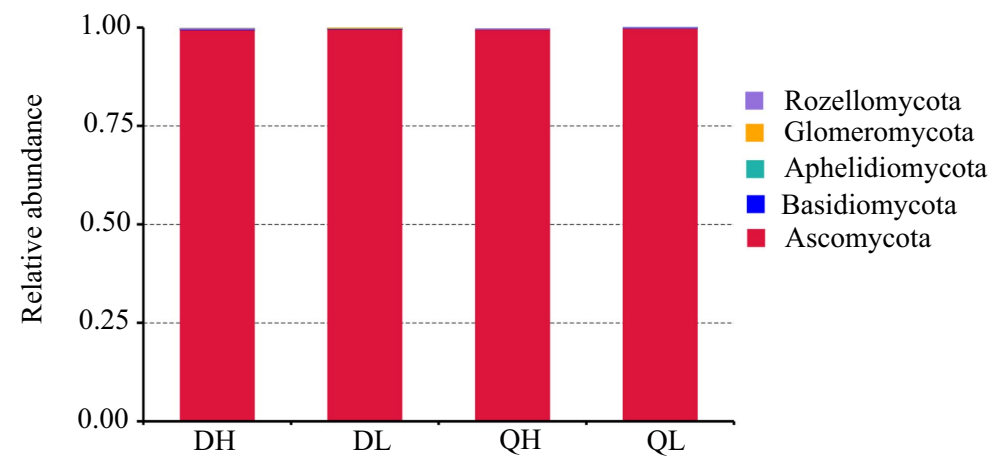

C

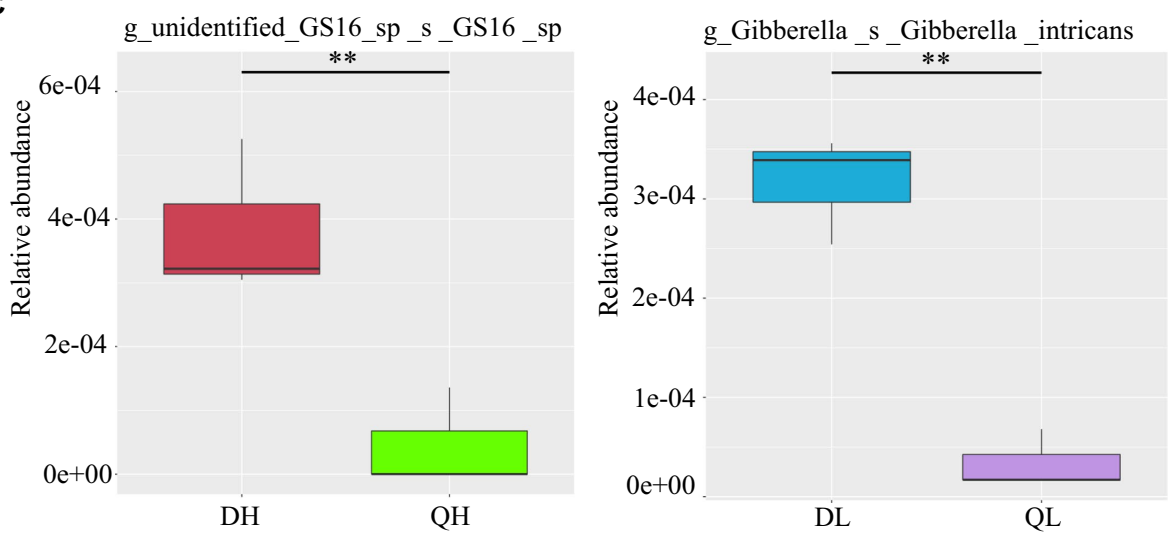

FIGURE 5 | Relative abundance of fungal taxonomic units in Du Shi and Qing Zhou Mi Tao roots grown at high and low P conditions. (A) Numbers of fungal OTUs in Du Shi and Qing Zhou Mi Tao roots. (B) Relative abundance of fungal taxa at the phylum level in Du Shi and Qing Zhou Mi Tao roots. (C) Specific taxa enriched in Du Shi and Qing Zhou Mi Tao roots under HP or LP conditions. **p<0.01, Student's $t$-test.

TABLE 2 | Root fungal abundance and diversity in peach rootstocks under HP and LP conditions.

\begin{tabular}{llll}
\hline Sample group & Coverage (\%) & Chao 1 & Shannon \\
\hline $\mathrm{DH}$ & $99.99 \pm 0.00 \mathrm{a}$ & $47.13 \pm 4.52 \mathrm{a}$ & $0.78 \pm 0.04 \mathrm{a}$ \\
$\mathrm{DL}$ & $99.98 \pm 0.00 \mathrm{a}$ & $43.12 \pm 2.78 \mathrm{a}$ & $0.70 \pm 0.05 \mathrm{a}$ \\
$\mathrm{QH}$ & $99.99 \pm 0.00 \mathrm{a}$ & $41.88 \pm 1.15 \mathrm{a}$ & $0.88 \pm 0.11 \mathrm{a}$ \\
$\mathrm{QL}$ & $99.99 \pm 0.00 \mathrm{a}$ & $30.27 \pm 1.11 \mathrm{~b}$ & $0.83 \pm 0.12 \mathrm{a}$ \\
\hline
\end{tabular}

Within a column, values followed by different letters are significantly different $(p<0.05)$.

further study is needed (Li et al., 2020). Under low P level, the abundance of gibberellus in roots of Du Shi was significantly higher than that of Qing Zhou Mi Tao (Figure 5C). Gibberellus is a plant rhizosphere growth-promoting microorganism that secretes gibberellin, a plant hormone that promotes plant growth (Yuan et al., 2020). Peach rootstock genotypes influence the endophytic fungal community (Figure 4B). It has been found that significant differences in fungal communities existed in Arabidopsis roots and leaves (Bai et al., 2015). The same is true in the stalk of sugar cane (De Souza et al., 2016). In addition, we observed that there were no significant differences in the fungal communities of the same peach rootstock under different $P$ supply levels (Figure 4). In a similar study (Ding et al., 2016), the tall fescue-endophyteinfected varieties in soils had no influence on rhizosphere soil microbial community structure. The structures of AMF 
communities in maize roots are significantly influenced by growth stage (6-leaf collar, 13-leaf collar, and kernel dough stages), but not by P fertilizer levels (Liu et al., 2016b). Liu et al. (2016b) also indicated that crop phenology may be a stronger determinant than $\mathrm{P}$ application in shaping the AMF community structure in roots. One reason why $\mathrm{P}$ levels in our study did not affect fungal community may be due to lack of dynamic responses when only sampling at one time point during plant development.

\section{DATA AVAILABILITY STATEMENT}

The original contributions presented in the study are publicly available. This data can be found here: National Center for Biotechnology Information (NCBI) BioProject database under accession number PRJNA739805.

\section{REFERENCES}

Bai, Y., Müller, D. B., Srinivas, G., Garrido-Oter, R., Potthoff, E., Rott, M., et al. (2015). Functional overlap of the Arabidopsis leaf and root microbiota. Nature 528, 364-369. doi: 10.1038/nature16192

Berthrong, S. T., Yeager, C. M., Gallegos, G. L., Steven, B., Eichorst, S. A., Jackson, R. B., et al. (2014). Nitrogen fertilization has a stronger effect on soil $\mathrm{N}$-fixing bacterial communities than elevated atmospheric $\mathrm{CO}_{2}$. Appl. Environ. Microbiol. 80, 3103-3112. doi: 10.1128/AEM.04034-13

Bulgarelli, D., Rott, M., Schlaeppi, K., Themaat, E. V. L. V., Ahmadinejad, N., Assenza, F., et al. (2012). Revealing structure and assembly cues for Arabidopsis root-inhabiting bacterial microbiota. Nature 488, 91-95. doi: 10.1038/nature11336

Caporaso, G., Kuczynski, J., Stombaugh, J., Bittinger, K., Bushman, F. D., Costello, E. K., et al. (2010). QIIME allows analysis of high-throughput community sequencing data. Nat. Methods 7, 335-336. doi: 10.1038/nmeth.f.303

Chai, X. F., Li, X., Wang, X. N., and Wang, H. (2019). Apple rootstocks with different phosphorus efficiency exhibit alterations in rhizosphere bacterial structure. J. Appl. Microbiol. 128, 1460-1471. doi: 10.1111/jam.14547

Cong, W. F., Suriyagoda, L. D. B., and Lambers, H. (2021). Tightening the phosphorus cycle through phosphorus-efficient crop genotypes. Trends Plant Sci. 25, 967-975. doi: 10.1016/j.tplants.2020.04.013

Cordell, D., Drangert, J. Q., and White, S. (2009). The story of phosphorus: global food security and food for thought. Glob. Environ. Chang. 19, 292305. doi: 10.1016/j.gloenvcha.2008.10.009

Crombez, H., Motte, H., and Beeckman, T. (2019). Tackling plant phosphate starvation by the roots. Dev. Cell 48, 599-615. doi: 10.1016/j.devcel.2019.01.002

De Souza, R. S. C., Okura, V. K., Armanhi, J. S. L., Jorrín, B., Lozano, N., Silva, M. J. D., et al. (2016). Unlocking the bacterial and fungal communities assemblages of sugarcane microbiome. Sci. Rep. 6:28774. doi: 10.1038/ srep 28774

Ding, N., Guo, H., Kupper, V. J., and McNear, H. M. (2016). Shoot specific fungal endophytes alter soil phosphorus $(\mathrm{P})$ fractions and potential acid phosphatase activity but do not increase P uptake in tall fescue. Plant Soil 401, 291-305. doi: 10.1007/s11104-015-2757-1

Du, Y. G., Ke, X., Dai, L. C., and Cao, G. M. (2020). Moderate grazing increased alpine meadow soils bacterial abundance and diversity index on the Tibetan Plateau. Ecol. Evol. 10, 8681-8687. doi: 10.1002/ece3.6563

García-López, A. M., and Delgado, A. (2016). Effect of Bacillus subtilis on phosphorus uptake by cucumber as affected by iron oxides and the solubility of the phosphorus source. Agric. Food Sci. 25, 216-224. doi: 10.23986/ afsci. 56862

García-López, A. M., Ramiro, R., and Delgado, A. (2021). The adsorbent capacity of growing media does not constrain myo-inositol hexakiphosphate hydrolysis but its use as a phosphorus source by plants. Plant Soil 459, 277-288. doi: $10.1007 /$ s11104-020-04764-1

\section{AUTHOR CONTRIBUTIONS}

$\mathrm{YZ}$ conducted the experiments, analyzed the data, and prepared the manuscript. XL analyzed the data. JG, JZ, SW, and ZZ performed the collection and processing of samples and analyzed the data. QJ and RF coordinated the experiments. All authors have read and agreed to the final version of the manuscript.

\section{FUNDING}

This research was supported by the China Agriculture Research System of Peach (CARS-30), Beijing Academy of Agriculture and Forestry Sciences Innovation Capability Construction Special Project (KJCX20200114), and Beijing Academy of Agriculture and Forestry Sciences Innovation Capability Construction Special Project (KJCX20210701).

Hinsinger, P. (2001). Bioavailability of soil inorganic P in the rhizosphere as affected by root-induced chemical changes: a review. Plant Soil 237, 173-195. doi: 10.1023/A:1013351617532

Hu, Y. W., Duan, C. Q., Fu, D. G., and Wu, X. N. (2020). Structure of bacterial communities in phosphorus-enriched rhizosphere soils. Appl. Sci. 10, 6387. doi: $10.3390 /$ app 10186387

Hu, Y. J., Xia, Y. H., Sun, Q., Liu, K. P., Chen, X. B., Ge, T. D., et al. (2018) Effects of long-term fertilization on phoD-harboring bacterial community in karst soils. Sci. Total Environ. 628, 53-63. doi: 10.1016/j.scitotenv.2018.01.314

Jacoby, R., Peukert, M., Succurro, A., Koprivova, A., and Kopriva, S. (2017). The role of soil microorganisms in plant mineral nutrition-current knowledge and future directions. Front. Plant Sci. 19:1617. doi: 10.3389/fpls.2017.01617

Johnston, A. E., Poulton, P. R., Fixen, P. E., and Curtin, D. (2014). Phosphorus: its efficient use in agriculture. Adv. Agron. 123, 177-228. doi: 10.1016/ B978-0-12-420225-2.00005-4

Li, J., Bao, H. Y., Xing, W. J., Yang, J., Liu, R. F., Wang, X., et al. (2020). Succession of fungal dynamics and their influence on physicochemical parameters during pig manure composting employing with pine leaf biochar. Bioresour. Technol. 297:122377. doi: 10.1016/j.biortech.2019.122377

Li, Y., Chen, L., and Wen, H. (2015). Changes in the composition and diversity of bacterial communities 13 years after soil reclamation of abandoned mine land in eastern China. Ecol. Res. 30, 357-366. doi: 10.1007/s11284-014-1230-6

Li, H., Zhang, W., Zhang, F., Du, F., and Li, L. (2010). Analysis of the changes in chemical fertilizer use and efficiency of the main grain crops in China. Plant Nutr. Fertil. Sci. 16, 1136-1143. doi: 10.11674/zwyf.2010.0514

Liu, C. S., Li, W., Liu, L. H., Yu, H. T., Liu, F., and Lee, D. J. (2020). Autotrophic induced heterotrophic bioreduction of bromate in use of elemental sulfur or zerovalent iron as electron donor. Bioresour. Technol. 317:124015. doi: 10.1016/j.biortech.2020.124015

Liu, H. T., White, P. J., and Li, C. J. (2016a). Biomass partitioning and rhizosphere responses of maize and faba bean to phosphorus deficiency. Crop Pasture Sci. 67, 847-856. doi: 10.1071/CP16015

Liu, W., Zhang, Y., Jiang, S., Deng, Y., Christie, P., Murray, P. J., et al. (2016b). Arbuscular mycorrhizal fungi in soil and roots respond differently to phosphorus inputs in an intensively managed calcareous agricultural soil. Sci. Rep. 6:24902. doi: 10.1038/srep24902

Marasco, R., Rolli, E., Fusi, M., Michoud, G., and Daffonchio, D. (2018) Grapevine rootstocks shape underground bacterial microbiome and networking but not potential functionality. Microbiome 6:3. doi: 10.1186/ s40168-017-0391-2

Mendes, L. W., Kuramae, E. E., Navarrete, A. A., Van Veen, J. A., and Tsai, S. M. (2014). Taxonomical and functional microbial community selection in soybean rhizosphere. ISME J. 8, 1577-1587. doi: 10.1038/ismej.2014.17

Niu, Y., Zhang, M. Y., Bai, S. H., Xu, Z. H., Liu, Y. Q., Chen, F. S., et al. (2020). Successive mineral nitrogen or phosphorus fertilization alone significantly altered bacterial community rather than bacterial biomass in 
plantation soil. Appl. Microbiol. Biotechnol. 104, 7213-7224. doi: 10.1007/ s00253-020-10761-2

Pankratov, T. A., Ivanova, A. O., Dedysh, S. N., and Liesack, W. (2011). Bacterial populations and environmental factors controlling cellulose degradation in an acidic sphagnum peat. Environ. Microbiol. 13, 1800-1814. doi: 10.1111/j. 1462-2920.2011.02491.X

Peng, Y. F., Peng, Y., Zhang, Y., Sun, G., Ning, P., Li, X. X., et al. (2012). Temporal and spatial dynamics in root length density of field-grown maize and NPK in the soil profile. Field Crop Res. 131, 9-16. doi: 10.1016/j.fcr.2012.03.003

Poudel, R., Jumpponen, A., Kennelly, M. M., Rivard, C. L., Gomez-Montano, L., and Garrett, K. A. (2019). Rootstocks shape the rhizobiome: rhizosphere and endosphere bacterial communities in the grafted tomato system. Appl. Environ. Microbiol. 85, e01765-e01800. doi: 10.1128/AEM.01765-18

Powers, S., Mirsky, E., Bandaranayake, A., Thavarajah, P., and Thavarajah, D. (2020). Field pea (Pisum sativum L.) shows genetic variation in phosphorus use efficiency in different P environments. Sci. Rep. 10:18940. doi: 10.1038/ s41598-020-75804-0

Quast, C., Pruesse, E., Yilmaz, P., Gerken, J., Schweer, T., Yarza, P., et al. (2013). The SILVA ribosomal RNA gene database project: improved data processing and web-based tools. Nucleic Acids Res. 41, D590-D600. doi: 10.1093/nar/gks1219

Raghothama, K. G., and Karthikeyan, A. S. (2005). Phosphate acquisition. Plant Soil 274, 37-49. doi: 10.1007/s11104-004-2005-6

Samaddar, S., Chatterjee, P., Truu, J., Anandham, R., Kim, S., and Sa, T. (2019). Long-term phosphorus limitation changes the bacterial community structure and functioning in paddy soils. Appl. Soil Ecol. 134, 111-115. doi: 10.1016/j. apsoil.2018.10.016

Schoch, C. L., Seifert, K. A., Huhndorf, S., Robert, V., Spouge, J. L., Levesque, C. A., et al. (2012). Nuclear ribosomal internal transcribed spacer (ITS) region as a universal DNA barcode marker for fungi. Proc. Natl. Acad. Sci. U. S. A. 109, 6241-6246. doi: 10.1073/pnas.1117018109

Shi, J., Zhang, B. G., Qiu, R., Lai, C. Y., Jiang, Y. F., He, C., et al. (2019). Microbial chromate reduction coupled to anaerobic oxidation of elemental sulfur or zerovalent iron. Environ. Sci. Technol. 53, 3198-3207. doi: 10.1021/ acs.est.8b05053

Souza, A. D. G., Smiderle, O. J., Menegatti, R. D., Lima, M. A. C. D., and Jo, B. V. (2019). Physiological quality in seeds of peach rootstock classified by weight and stored for different periods. Recent Pat. Food Nutr. Agric. 10, 124-130. doi: 10.2174/2212798410666181120122624

Su, J. Q., Ding, L. J., Xue, K., Yao, H. Y., Quensen, J., Bai, S. J., et al. (2015). Long-term balanced fertilization increases the soil microbial functional diversity in a phosphorus-limited paddy soil. Mol. Ecol. 24, 136-150. doi: 10.1111/mec. 13010

Wang, H., Yang, A., Yang, G., Zhao, H. Y., Xie, F. T., Zhang, H. J., et al. (2021). Screening and identification of soybean varieties with high phosphorus efficiency at seedling stage. Oil Crop Sci. 6, 41-49. doi: 10.1016/j. ocsci.2021.03.001
Wei, Z., Hao, Z., Li, X., Guan, Z., Cai, Y., and Liao, X. (2019). The effects of phytoremediation on soil bacterial communities in an abandoned mine site of rare earth elements. Sci. Total Environ. 670, 950-960. doi: 10.1016/j. scitotenv.2019.03.118

Yu, P., Wang, C., Baldauf, J. A., Tai, H. H., Gutjahr, C., Hochholdinger, F., et al. (2017). Root type and soil phosphate determine the taxonomic landscape of colonizing fungi and the transcriptome of field-grown maize roots. New Phytol. 217, 1240-1253. doi: 10.1111/nph.14893

Yuan, R. W., Liu, L., Zhang, R., and Fan, S. Y. (2020). The interaction mechanism between plant rhizosphere secretion and soil microbe: a review. Chin. Agric. Sci. Bull. 36, 26-35. doi: 10.11924/j.issn.1000-6850.casb18090023

Yushchuk, O., Homoniuk, V., Datsiuk, Y., Ostash, B., and Fedorenko, V. (2020). Development of a gene expression system for the uncommon actinomycete Actinoplanes rectilineatus NRRLB-16090. J. Appl. Genet. 61, 141-149. doi: 10.1007/s13353-019-00534-7

Zhang, W., Liu, S., Zhang, M., Li, Y., Sheng, K., and Xu, Z. (2019). Phyllostachys edulis (moso bamboo) rhizosphere increasing soil microbial activity rather than biomass. J. Soils Sediments 19, 2913-2926. doi: 10.1007/s11368-019-02334-2

Zhang, B., Rui, Q., Lu, L., Xi, C., and Ren, Z. J. (2018). Autotrophic vanadium (V) bioreduction in groundwater by elemental sulfur and zerovalent iron. Environ. Sci. Technol. 52, 7434-7442. doi: 10.1021/acs.est.8b01317

Zhang, Y., Yu, P., Peng, Y. F., Li, X. X., Chen, F. J., and Li, C. J. (2012). Fine root patterning and balanced inorganic phosphorus distribution in the soil indicate distinctive adaptation of maize plants to phosphorus deficiency. Pedosphere 22, 870-877. doi: 10.1016/S1002-0160(12)60073-3

Zhao, D. Y., Zheng, S. S., Kashif, N. M., Niu, J. Q., Ning, W., Li, Z. J., et al. (2018). Screening wheat genotypes for better performance on reduced phosphorus supply by comparing glasshouse experiments with field trials. Plant Soil 430, 349-360. doi: 10.1007/s11104-018-3739-x

Conflict of Interest: The authors declare that the research was conducted in the absence of any commercial or financial relationships that could be construed as a potential conflict of interest.

Publisher's Note: All claims expressed in this article are solely those of the authors and do not necessarily represent those of their affiliated organizations, or those of the publisher, the editors and the reviewers. Any product that may be evaluated in this article, or claim that may be made by its manufacturer, is not guaranteed or endorsed by the publisher.

Copyright (c) 2021 Zhang, Liu, Guo, Zhao, Wang, Zheng, Jiang and Ren. This is an open-access article distributed under the terms of the Creative Commons Attribution License (CC BY). The use, distribution or reproduction in other forums is permitted, provided the original author(s) and the copyright owner(s) are credited and that the original publication in this journal is cited, in accordance with accepted academic practice. No use, distribution or reproduction is permitted which does not comply with these terms. 